Brit. J. industr. Med., 1956, 13, 210.

\title{
DETERMINATION OF ATMOSPHERIC BENZENE CONCENTRATION BY DISPLACEMENT FOLLOWING ADSORPTION ON SILICA GEL
}

\author{
BY \\ PER ÖVRUM \\ From the Department of Industrial Health, the National Institute of Public Health, Tomteboda, Sweden
}

(RECEIVED FOR PUBLICATION MARCH 13, 1956)

In industries which employ solvents containing benzene, determination of the atmospheric content of this substance is an important and constant health problem.

Many of the methods of assessing benzene concentration described in the literature, including those of Jacobs (1949) and Elkins (1950), entail determination of the total aromatic content, and estimation of the atmospheric benzene concentration according to these methods frequently requires more or less time-consuming laboratory work. Some methods, such as absorption in alcohol or other solvents, necessitate effective chilling of certain parts of the apparatus during sampling in order to minimize loss of benzene. This may be difficult in field work.

Tiselius (1943) introduced a technique which may be used for various analytical purposes. The principle is that the fluid mixture to be analysed is adsorbed on, for instance, a column. of silica gel, and then displaced by a substance which is more strongly adsorbed than any of the components of the mixture.

I have tested the displacement technique in analyses of atmospheric benzene concentration. Benzene vapour was adsorbed on silica gel. The eluent was absolute alcohol. The content of benzene in the percolate was determined. The advantages of the method are ease of sampling and concentration of the atmospheric benzene in a small quantity ( 1 to $5 \mathrm{ml}$.) of alcohol, which permits greater precision in the final spectrophotometric determination. Further, it is possible by means of absorption spectra to identify benzene in the ultra-violet region.

\section{Preparation of Silica Gel}

It is important that the gel should be free from impurities with absorption spectra in the ultra-violet region of 250 to $275 \mathrm{~m} \mu$. This is because the final determination of benzene is made according to the
American Society for Testing Materials designation, D 1017-49T (ultra-violet absorption), except that absolute alcohol is used instead of iso-octane. The presence of such impurities may be detected by forcing absolute alcohol through a glass tube packed with activated silica gel and then measuring the absorptivity of the percolate in the region of 250 to $275 \mathrm{~m} \mu$ of an ultra-violet spectrophotometer. Three brands of silica

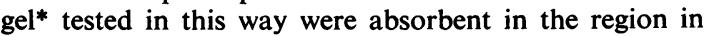
question. By treating the silica gel in a Soxhlet apparatus with absolute alcohol, however, the absorbance could be reduced to a value which did not affect the measurements. The gel was then reactivated by drying for four hours in vacuo (water suction) at 135 to $140^{\circ} \mathrm{C}$.

\section{Adsorptive Capacity of the Silica Gel}

The apparatus sketched in Fig. 1 was used to test the adsorptive capacity of the silica gel. When air is sucked through the apparatus, a weighed sample of benzene placed in tube $\mathrm{A}$ vapourizes and is adsorbed on the silica gel in tube $\mathrm{C}$.

It was found that the adsorbed benzene tended to percolate through the gel with the air stream. Hence it was important to elucidate the velocity of this benzene movement. Two problems thereby arose and were investigated.

Problem 1.-Does the speed of benzene percolation alter when the air flow and the diameter of the adsorption tube are constant but the quantity of gel is varied, and is there a relationship between the amount of gel and the maximum time during which air can be sucked through the adsorption tube without loss of benzene ?

Problem 2.- How does variation of the air flow through the silica gel affect the velocity of benzene percolation when the diameter of the tube and the quantity of gel are constant?

An air flow of 0.188 litres per minute was used in all the investigations of problem 1 . In the first series of experiments the quantity of gel was $1 \cdot 11 \mathrm{~g}$. and the length

* Silica gels used were obtained from the Davidson Chemical Corporation, Baltimore 3, U.S.A. (mesh size 28-200 and " thru 200 "), and Silica Gel Ltd., Garrick Street, London, W.C.2 (mesh size 100-200). 


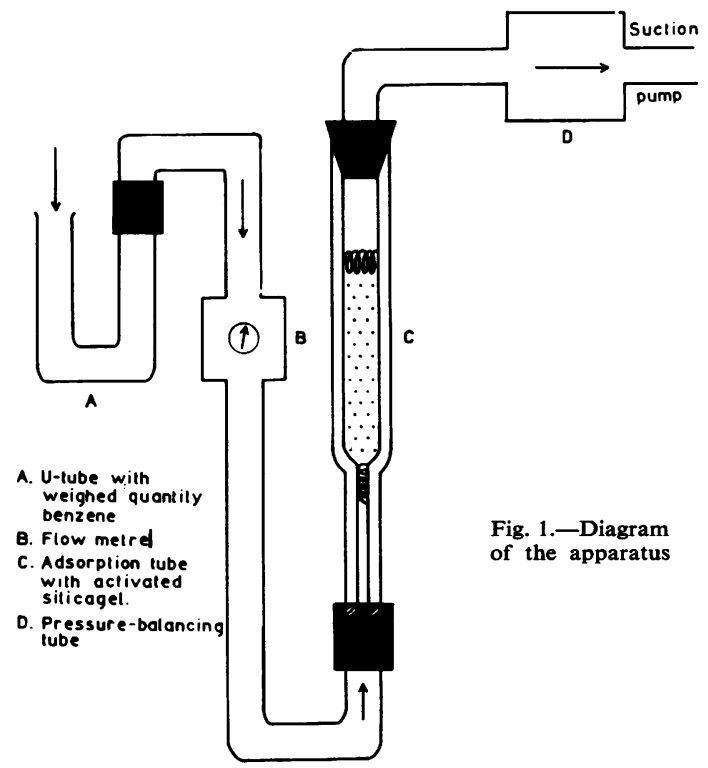

of the gel column $50 \mathrm{~mm}$. In the second series the corresponding figures were $2 \cdot 22 \mathrm{~g}$. and $100 \mathrm{~mm}$. The inner diameter of the adsorption tube was $6.8 \mathrm{~mm}$. in both series.

Air was sucked through the apparatus for a fixed time, after which the amount of benzene adsorbed on the gel was determined. If the yield was equal to the quantity placed in the U-tube, the period of suction was lengthened until loss of benzene was registered. The maximum time during which the benzene-containing air could be sucked through the gel without loss was 45 minutes in these experiments. The velocity of benzene through the silica gel was accordingly determined. The results are presented in Table 1.

Loss began after about 90 minutes in the $100 \mathrm{~mm}$.

TABLE 1

VELOCITY OF BENZENE THROUGH SILICA GEL DURING CONSTANT AIR FLOW

\begin{tabular}{c|c|c}
\hline \multirow{2}{*}{ Time } & \multicolumn{2}{|c}{ Yield (\%) } \\
\cline { 2 - 3 } & $\begin{array}{c}\text { 1.11 g. gel } \\
50 \mathrm{~mm} .\end{array}$ & $\begin{array}{r}2 \cdot 22 \mathrm{~g} \cdot \mathrm{gel} \\
100 \mathrm{~mm} .\end{array}$ \\
\hline 30 & 98 & 99 \\
45 & 97 & 98 \\
48 & 94 & 100 \\
53 & 67 & 98 \\
60 & 27 & 98 \\
70 & - & 99 \\
90 & - & 96 \\
105 & - & 85 \\
120 & - & 65 \\
140 & - & 35. \\
\hline
\end{tabular}

Inner diameter of adsorption tube $6.8 \mathrm{~mm}$

Velocity of air flow $0 \cdot 188 \mathrm{l} . / \mathrm{min}$.

column of gel and after about 45 minutes in the $50 \mathrm{~mm}$. column. Thus in both cases the benzene percolated through the gel at a rate of about $1 \cdot 1 \mathrm{~mm}$. per minute. Table 2 shows the velocity of benzene percolation when the inner diameter of the adsorption tube was varied.

TABLE 2

VELOCITY OF BENZENE PERCOLATION WITH ADSORPTION TUBES OF VARIED DIAMETER

\begin{tabular}{c|c|c|c|c}
\hline $\begin{array}{c}\text { Diameter of } \\
\text { Adsorption } \\
\text { Tube (mm.) }\end{array}$ & $\begin{array}{c}\text { Silica } \\
\text { Gel } \\
\text { (g.) }\end{array}$ & $\begin{array}{c}\text { Maximum* } \\
\text { Time } \\
\text { (min.) }\end{array}$ & $\begin{array}{c}\text { Benzene Move- } \\
\text { ment through } \\
\text { Gel } \\
\text { (mm./min.) }\end{array}$ & $\begin{array}{c}\text { Maximum } \\
\text { Time/ } \\
\text { Gel } \\
\text { Quantity }\end{array}$ \\
\hline 6.8 & $1 \cdot 11$ & 45 & $1 \cdot 1$ & 41 \\
10.4 & $2 \cdot 59$ & 100 & 0.5 & 39 \\
$15 \cdot 1$ & 5.25 & 240 & 0.2 & 46 \\
\hline
\end{tabular}

* Before benzene loss is registered.

When the air flow through the gel and the diameter of the adsorption tube were constant, therefore the percolation rate of benzene was also constant. Further, the quotient $\frac{\text { maximum time }}{\text { gel quantity }}$ was shown to be about 42 . This constant is fully adequate to calculate a time margin for field sampling (e.g., $10 \mathrm{~g}$. gel gives a maximum time of $42 \times 10=420$ minutes).

The apparatus for the experiments to solve problem 2 was the same as for problem 1 , except that the diameter of the adsorption tube was always $10.4 \mathrm{~mm}$. and the length of the gel column $50 \mathrm{~mm}$. The results are presented in Fig. 2.

As the flow of air increased from 0 to 0.2 litres per minute, the velocity of benzene percolation showed an almost linear increase (Fig. 2). With more rapid air flow, however, the curve of benzene movement rose more sharply.

\section{Test Apparatus}

The above principles for analysis of atmospheric benzene content were tested with the apparatus illustrated in Fig. 1.

The air to be analysed is sucked through the inlet pipe, the flow meter, and the adsorption tube, which is filled with activated silica gel. The pressure-balancing tube has an extra air intake, by means of which the pressure, and consequently also the air flow through the flow meter and the adsorption tube can be regulated.

The flow meter should be graduated to show about 0.15 to 0.25 litres per minute with an accuracy of $\pm 2 \%$.

The adsorption tube consists of a wide and a narrower section. In my experiments the inner diameter of the upper section generally was $10.4 \mathrm{~mm}$. (in some cases 6.8 or $15.1 \mathrm{~mm}$.) and that of the lower section $1.5 \mathrm{~mm}$.

Glass wool is placed at the junction of the sections to prevent the gel escaping into the capillary. The construction of the apparatus must permit easy changing of the adsorption tube. It may be connected to the pressurebalancing tube with, for instance, a pierced rubber stopper. The flow meter may be connected by means of a short tube of plastic or rubber material insoluble in benzene.

The pressure-balancing tube has two functions. It eliminates any pressure variations from the vacuum pump and by means of the extra air intake can alter the negative pressure. 
Fig. 2-Results of experiments to solve problem 2.

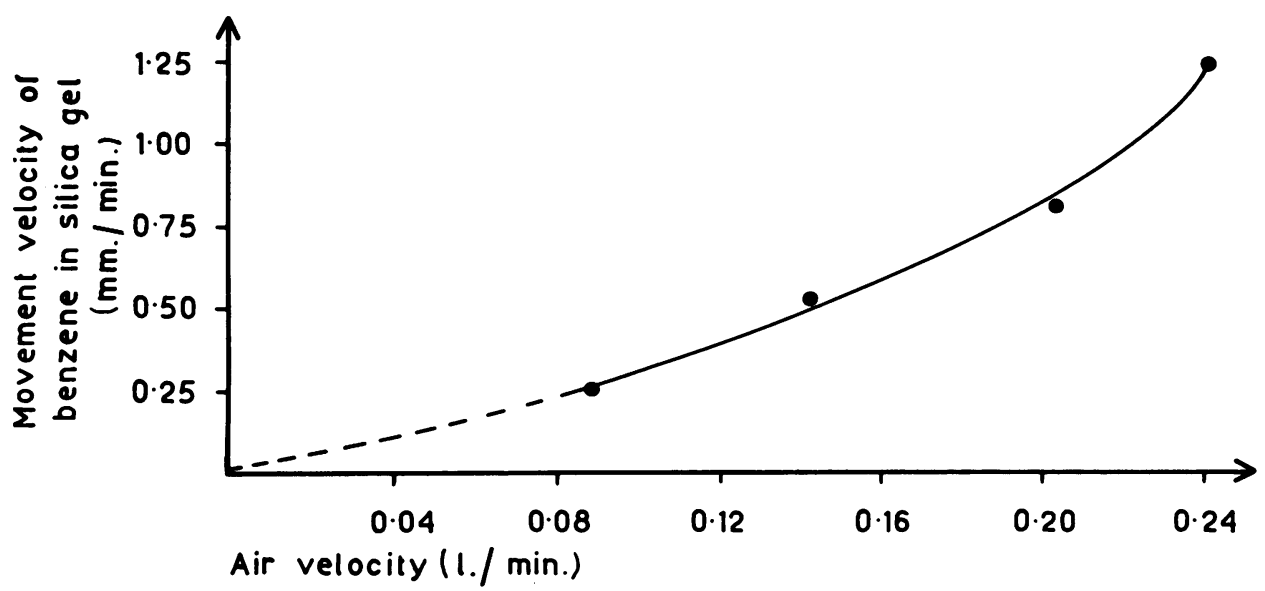

The vacuum pump should be capable of a negative pressure of at least $100 \mathrm{~mm}$. $\mathrm{Hg}$ in order to counteract the resistance in the adsorption tube. The pump must also be able to function continuously for several hours with this load.

\section{Sampling}

The adsorption tube is filled with about $5 \mathrm{~g}$. of silica gel. The gel is well packed, preferably with a vibrator, until the volume does not diminish further. To hold the gel in position cotton wool is packed tightly above it with a glass rod. The adsorption tube is placed in the apparatus and suction of air is begun. From the flow meter the volume of air per unit of time can be calculated. When the desired volume has passed through the adsorption tube the tube is removed and placed in a stand. A volumetric flask with a capacity of $5 \mathrm{ml}$. and containing $1 \mathrm{ml}$. of absolute alcohol is placed under the tube. The tip of the capillary should be below the surface of the alcohol.

Into the upper part of the adsorption tube 5 to $10 \mathrm{ml}$. of absolute alcohol is then poured. The passage of the alcohol through the gel can be accelerated by weak positive pressure from an $\mathrm{N}_{2}$ bomb. The displacement should take five to 10 minutes. The alcohol forces the adsorbed benzene through the column of gel and into the flask. To ensure that no benzene remains in the adsorption tube, 1 to $2 \mathrm{ml}$. of the eluting alcohol should also be forced down into the flask.

The volumetric flask is then filled to the 5-ml. mark with absolute alcohol. The benzene is identified and measured with a spectrophotometer. (The type used was a Beckman model DU.) As stated earlier, the benzene content was determined according to A.S.T.M. designation D 1017-49T (UV absorption). The spectroscopic solvent, however, was absolute alcohol instead of iso-octane. (Absolute alcohol which has been treated identically with the sample under analysis may also be used as the spectroscopic solvent.)

When sampling air in working premises a sufficient number of prepared adsorption tubes should be available. These should be sealed to prevent premature entry of air. The displacement and analytical procedures are performed later in the laboratory.

Testing the Method with Known Concentrations of Benzene

Series A.-Two connected carboys, each with a capacity of 63 litres and with fans for mixing gas, comprised the "gas chamber". A mixture of benzene and n-heptane was pipetted into the carboys. The findings from these tests are presented in Table 3.

TABLE 3

RESULTS OF TESTS WITH KNOWN CONCENTRATIONS OF BENZENE

\begin{tabular}{|c|c|c|c|c|c|}
\hline $\begin{array}{l}\text { Test } \\
\text { No. }\end{array}$ & $\begin{array}{l}\text { Weighed Quantity } \\
\text { of Benzene } \\
\text { (mg./1.) }\end{array}$ & p.p.m. & $\begin{array}{l}\text { Recovered } \\
\text { Benzene } \\
\text { (mg./1.) }\end{array}$ & p.p.m. & $\begin{array}{c}\text { Yield } \\
(\%)\end{array}$ \\
\hline $\begin{array}{r}1 \\
2 \\
3 \\
4 \\
5 \\
6 \\
7 \\
8 \\
9 \\
10 \\
11 \\
12 \\
13 \\
14 \\
15 \\
16 \\
17\end{array}$ & $\begin{array}{l}0.0030 \\
0.0030 \\
0.0168 \\
0.2047 \\
0.2047 \\
0.2047 \\
0.2047 \\
1.093 \\
1.093 \\
1.093 \\
1.093 \\
1.093 \\
1.093 \\
0.9005 \\
0.9145 \\
1.280 \\
1.280\end{array}$ & $\begin{array}{c}0 \cdot 9 \\
0 \cdot 9 \\
5 \cdot 2 \\
63 \cdot 0 \\
63 \cdot 0 \\
63 \cdot 0 \\
63 \cdot 0 \\
336 \\
336 \\
336 \\
336 \\
336 \\
336 \\
277 \\
282 \\
394 \\
394\end{array}$ & $\begin{array}{l}0.0028 \\
0.0027 \\
0.0162 \\
0.2013 \\
0.2020 \\
0.1985 \\
0.2008 \\
1.060 \\
1.066 \\
1.076 \\
1.082 \\
1.068 \\
1.068 \\
0.8951 \\
0.9108 \\
1.310 \\
1.300\end{array}$ & $\begin{array}{l}0 \cdot 9 \\
0 \cdot 8 \\
5 \cdot 0 \\
62 \cdot 0 \\
62 \cdot 2 \\
61 \cdot 1 \\
61 \cdot 8 \\
326 \\
328 \\
331 \\
333 \\
329 \\
329 \\
276 \\
280 \\
403 \\
400\end{array}$ & $\begin{array}{l}94 \\
90 \\
96 \cdot 3 \\
98 \cdot 3 \\
98 \cdot 7 \\
97 \cdot 0 \\
98 \cdot 1 \\
97.0 \\
97 \cdot 5 \\
98 \cdot 4 \\
99 \cdot 0 \\
97 \cdot 7 \\
97 \cdot 7 \\
99 \cdot 4 \\
99 \cdot 6 \\
102.3 \\
101.6\end{array}$ \\
\hline
\end{tabular}

The mean yield in series $A$, therefore, was $97 \cdot 8 \pm 0.7 \%$ (range 90 to $102 \cdot 3 \%$ ).

Series B.-With the apparatus shown in Fig. 1, in which a weighed sample of benzene placed in the U-tube is vapourized in the air flow, 27 tests were made. The quantity of benzene ranged from 1.06 to $1.28 \mathrm{mg}$. The mean yield was $98 \cdot 3 \pm 0 \cdot 3 \%$ (range 96 to $100 \cdot 8 \%$ ). 


\section{Discussion}

The method described here was shown to permit accurate quantitative study of atmospheric benzene. Concentrations as low as $0.003 \mathrm{mg}$. per litre $(0.9$ p.p.m.) were determined without difficulty and still lower benzene concentrations may readily be analysed if the quantity of gel is increased. An advantage of the method is that identification and quantitative estimation of atmospheric benzene can proceed simultaneously, even when the solvents employed have a very low benzene content.

The principles of the analytic procedure may also be applied in the determination of many other solvents in vapour form. Other adsorption media, eluents, and methods for the final analysis may then be necessary.

\section{Summary}

The displacement technique was used for determining atmospheric benzene concentrations. Air is sucked into a specially-shaped tube filled with activated silica gel. Adsorbed benzene is forced out of the gel by absolute alcohol and is collected in a volumetric flask. The concentration is then determined according to the American Society for Testing Metals designation D 1017-49T. The spectroscopic solvent, however, is absolute alcohol instead of iso-octane. The method was tested with benzene concentrations ranging from 0.003 to $1.28 \mathrm{mg}$. per litre of air. The mean yield was about $98 \%$.

The writer is indebted to Dr. R. Vesterberg and Mr. S. G. Blohm, B.Sc., for valuable assistance in the development of this method.

\section{REFERENCES}

Elkins, H. B. (1950). The Chemistry of Industrial Toxicology. Wiley,

Jacobs, M. B. (1949). The Analytical Chemistry of Industrial Poisons, Hazards, and Solvents. 2nd ed. (1st ed., 1941). Interscience, New York.

Tiselius, A. (1943). Ark. Kemi Min. Geol., 16A, No. 18. 